\title{
$\underline{\mathbf{P}-203}$
}

\section{Living Collections of Agricultural Conservatory Park, Universiti Putra Malaysia as a Mean of Ex-Situ Conservation}

\author{
Shamsul, K, Rishzuan, T*, Tajuddin, A.M, Nor Hafizah, R, Ahmad Ikhmal Razei, A.R and Ahmad \\ Hisham M.S \\ Biodiversity Unit, Institute of Bioscience, Universiti Putra Malaysia, 43400 Serdang Selangor; \\ E-mails: shamsulkhamis73@gmail.com,shamsul@ibs.upm.edu.my
}

UPM Agricultural Conservatory Park (ACP) was built on two hectares approximately of land which was originally a rubber (Hevea brasilliensis) plantation. The rubber plantation was established and maintained by the University Plantation Unit since the early 1980's. In 1996, the area was given to Institute of Bioscience for the development of a germplasm bank of selected herbal species. In line with the adjustment made within IBS in 2005, the scope and functions of the germplasm bank evolved into an Agricultural Conservatory Park, used mainly for research, teaching, reference and recreational purposes. Currently, the park has a collection of comprise nearly 500 indigenous including exotic species. The Agricultural Conservatory Park is divided into 11 zones based on the function, uses and types of plants available in Malaysia. This park plays an important role in the ex-situ conservation by promoting several initiatives, including the import of valuable native species (endemic, rare or new species) and local or international collaboration with governments and NGOs.

Keywords: Ex-situ conservation, indigenous species, zoning area, conservation status. 